\title{
PENERAPAN SOLUTION-FOCUSED BRIEF THERAPY DENGAN PENDEKATAN KELOMPOK UNTUK MEMPERBAIKI KONSEP DIRI REMAJA DI LPKA SLM
}

\author{
Jerry $^{1}$, Woro Kurnianingrum ${ }^{2}$ dan Debora Basaria ${ }^{3}$ \\ ${ }^{1}$ Program Studi Psikologi Profesi Jenjang Magister, Universitas Tarumanagara, Jakarta \\ Email: jerry.psi94@gmail.com \\ ${ }^{2}$ Fakultas Psikologi, Universitas Tarumanagara, Jakarta \\ Email: woro.kurnianingrum@gmail.com \\ ${ }^{3}$ Fakultas Psikologi, Universitas Tarumanagara, Jakarta \\ Email: deborab@fpsi.untar.ac.id
}

Masuk : 03-05-2019, revisi: 20-04-2020, diterima untuk diterbitkan : 23-04-2020

\begin{abstract}
Adolescents face the developmental task of 'identity versus identity confusion' which requires them to form a complete picture of themselves through the process of exploration of various types of work, values or ideologies and sexual identity. The concept of self begins to develop and stabilize in adolescence due to the formation of self-identity. Adolescents with negative self-concepts are more inclined to become deviants as a form of inability to adjust to the norms, causing them to be involved in legal issues. Adolescents in juvenile correctional facilities tend to show negative self-concepts compared to others. Negative views on themselves, coupled with being labelled as criminals results in low self-concept. Therefore, the aim of this study is to assess the effectiveness of solution-focused brief therapy with a group approach to improve self-concept in adolescents in SLM LPKA. The sampling technique used in this study was purposive sampling, which found five teenagers in SLM LPKA with low self-concepts as seen from DAP pre-test results. This study used one group pre-test post-test research design in which participants were administered DAP test before and after the intervention, and the results compared. Solution-focused brief therapy with a group approach in this study was conducted in five sessions for 60 minutes each. The five participants showed better self-concept after intervention. Changes could be seen during the intervention process and from the results of the DAP post-test. Based on the results obtained, it can be concluded that solution-focused brief therapy with a group approach is effective to improve self-concept in adolescents in SLM LPKA.
\end{abstract}

Keywords: solution-focused brief therapy, self-concept, adolescents

Remaja menghadapi tugas perkembangan 'identity versus identity confusion' yang menuntut mereka harus membentuk gambaran yang utuh mengenai diri sendiri melalui proses eksplorasi terhadap berbagai jenis pekerjaan, nilai atau ideologi serta identitas seksual. Konsep diri mulai berkembang dan stabil pada masa remaja karena mulainya pembentukkan identitas diri. Remaja yang memiliki konsep diri yang negatif mudah melakukan tindakan yang menyimpang sebagai bentuk ketidakmampuan dalam menyesuaikan diri dengan norma yang berlaku sehingga menyebabkan remaja terlibat dalam masalah hukum. Remaja yang berada dalam lembaga permasyarakatan dapat menunjukkan konsep diri yang cenderung negatif dibandingkan dengan remaja lainnya. Pandangan negatif terhadap dirinya dengan label remaja pidana membuat remaja memiliki konsep diri yang rendah. Oleh sebab itu, tujuan dari penelitian ini adalah untuk melihat efektivitas penerapan solution-focused brief therapy dengan pendekatan kelompok untuk memperbaiki konsep diri pada remaja di LPKA SLM. Teknik sampling yang digunakan dalam penelitian ini adalah purposive samping yaitu lima orang remaja di LPKA SLM yang memiliki konsep diri rendah dilihat dari pretest DAP. Penelitian ini menggunakan desain penelitian one group pre-test post-test dimana partisipan diberikan tes DAP untuk mengetahui perbandingan hasil sebelum dan sesudah pemberian intervensi. Solution-focused brief therapy dengan pendekatan kelompok dalam penelitian ini diberikan sebanyak lima sesi yang dilakukan selama 60 menit setiap sesi. Terlihat kelima partisipan menunjukkan konsep diri yang lebih baik. Perubahan dapat dilihat dari selama proses intervensi berlangsung dan hasil post-test DAP. Berdasarkan hasil yang didapatkan, maka dapat disimpulkan bahwa solution-focused brief therapy dengan pendekatan kelompok cukup efektif untuk memperbaiki konsep diri pada remaja di LPKA SLM.

Kata Kunci: solution-focused brief therapy, konsep diri, remaja 


\section{PENDAHULUAN}

\section{Latar Belakang}

Masa remaja dianggap sebagai periode peralihan atau transisi dari masa anak-anak ke masa dewasa dan diwarnai oleh berbagai perubahan fisik, kognitif dan psikososial (Berk, 2014; Papalia, Olds, \& Feldman, 2009). Masa remaja merupakan masa yang berlangsung ketika anak menginjak usia 11 atau 12 tahun hingga usia 19 tahun. Masa remaja merupakan masa yang berada di antara masa kanak-kanak dan masa dewasa ketika individual dihadapkan dengan serangkaian hambatan dan tantangan masa perkembangan (Papalia et al., 2009).

Menurut teori psikososial Erik Erikson, anak remaja menghadapi tugas 'identity versus identity confusion' yang menuntut mereka harus membentuk gambaran yang utuh mengenai diri sendiri melalui proses eksplorasi terhadap berbagai jenis pekerjaan, nilai atau ideologi serta identitas seksual (Papalia et al., 2009; Santrock, 2012). Erikson juga menyatakan bahwa fidelity yang tumbuh ketika remaja yang berhasil menyelesaikan tugas pada tahap 'identity versus identity confusion' akan meningkatkan keyakinan remaja mengenai diri mereka sendiri, nilai atau ideologi yang mereka adopsi serta arah tujuan hidup yang dipilih (Papalia et al., 2009; Santrock, 2012). Di sisi lain, kegagalan untuk memecahkan krisis identitas pada masa ini akan membuat remaja menarik diri dari lingkungan atau melakukan perubahan secara terus menerus pada gambaran mengenai diri berdasarkan kondisi lingkungan sosial (Santrock, 2012).

Calhoun dan Acocella (1999) mengatakan bahwa konsep diri merupakan gambaran mental individu, yang terdiri dari pengetahuan tentang diri, pengharapan, dan penilaian terhadap diri sendiri. Konsep diri bertambah stabil pada periode masa remaja. Konsep diri yang tidak stabil pada remaja dapat menyebabkan remaja memiliki konsep diri yang negatif. Remaja dengan konsep diri negatif tidak dapat mengenali diri dengan baik, serta tidak memahami kekurangan dan kelebihan dalam diri. Remaja yang memiliki konsep diri yang negatif mudah melakukan tindakan yang menyimpang sebagai bentuk ketidakmampuan remaja dalam menyesuaikan diri dengan norma dan aturan yang berlaku sehingga menyebabkan remaja terlibat dalam masalah hukum (Schoot \& Wang, 2011).

Bentuk-bentuk penyimpangan perilaku yang sering terjadi di masa remaja adalah tawuran, pencurian, penggunaan obat-obatan terlarang, dan perilaku seksual. Remaja yang terlibat dalam masalah hukum karena melakukan tindakan pelanggaran akan dimasukkan ke lembaga permasyarakatan atau rehabilitasi perkembangan (Papalia et al., 2009). Remaja yang berada dalam lembaga permasyarakatan dapat menunjukkan konsep diri yang cenderung negatif dibandingkan dengan remaja lainnya. Pandangan negatif terhadap dirinya dengan label remaja pidana membuat remaja memiliki konsep diri yang rendah (Schoot \& Wang, 2011). Remaja terpidana cenderung menganggap diri mereka tidak berguna dan tidak memiliki harapan, yang mengakibatkan mereka cenderung memiliki sikap yang pesimis, apatis, dan kurang inisiatif (Schoot \& Wang, 2011).

Hoag dan Burlingame (dalam Brabender, Fallon, \& Smolar, 2004) menemukan bahwa terapi kelompok efektif dalam meningkatkan keterampilan sosial, memperbaiki masalah sosial, locus of control, self-esteem, dan self-concept pada remaja. Salah satu pendekatan terapi kelompok yang juga dapat memperbaiki self-concept adalah solution-focused brief therapy (SFBT) dengan pendekatan kelompok. SFBT merupakan pendekatan client-directed therapeutic yang berfokus pada tujuan, diaplikasikan dalam waktu yang singkat, dan membantu individu fokus pada solusi dari pada masalah (Roeden, Maaskant, \& Curfs, 2014). SFBT melihat masalah sebagai akibat ketidakmampuan individu dalam melihat suatu peristiwa dari sudut pandang lain (Biggs \& Flett, 2005). Galbraith dan Alexander (2005) mengungkapkan bahwa SFBT dapat membantu individu 
meningkatkan konsep diri dengan menyadari kelebihan dan kekurangan diri mereka, merefleksikan tindakan dan proses berpikir, dan meningkatkan empati, serta sikap kooperatif dengan orang lain.

Berdasarkan penelitian Kim (2008) menunjukkan bahwa solution-focused brief therapy efektif untuk mengatasi permasalahan yang bersifat internalizing behavior seperti depresi, kecemasan, konsep diri, dan self-esteem. Penelitian dari Omotunde, Akporobaroh, dan Odunayo (2017) menunjukkan bahwa SFBT dapat meningkatkan konsep diri pada remaja. Hal ini disebabkan karena SFBT membantu remaja untuk fokus terhadap solusi yang bisa mereka lakukan untuk mengatasi masalahnya, bukan hanya terus menerus menekankan adanya masalah.

Rumusan masalah dalam penelitian ini adalah "Apakah penerapan solution-focus brief therapy dengan pendekatan kelompok dapat memperbaiki konsep diri pada remaja di Lembaga Pemasyarakatan Khusus Anak (LPKA) SLM?"

\section{METODE PENELITIAN}

\section{Partisipan dan Prosedur Penelitian}

Karakteristik partisipan dalam intervensi kelompok ini adalah remaja laki-laki dalam Lembaga Pembinaan Khusus Anak (LPKA) SLM, yang berusia tahun 15-18 tahun. Asesmen awal, yaitu tes draw a person (DAP) dan tes intelgensi (CFIT) dilakukan kepada 50 anak didik di LPKA SLM. Hasil tes DAP menjadi tolak ukur peneliti untuk menentukan partisipan yang menunjukkan kecenderungan memiliki konsep diri yang negatif dilihat dari ukuran gambar dan kelengkapan gambar, dan selanjutnya dilakukan observasi dan wawancara. Selanjutnya, di dapatkan 5 partisipan yang memenuhi karakteristik partisipan penelitian.

\section{Pengukuran Penelitian}

Instrumen penelitian yang digunakan dalam penelitian ini meliputi lembar informed consent, alat ukur Culture Fair Intelligence Test (CFIT) yang dikembangkan oleh Cattell (1949), Draw a Person (DAP) yang dikembangkan oleh Machover (1949), pensil HB, pulpen, lembar observasi, dan lembar wawancara. Tes CFIT digunakan untuk mengukur tingkat intelegensi masing-masing partisipan sehingga setiap partisipan didalam kelompok memiliki tingkat intelegensi yang sama sehingga dapat mengikuti proses terapi dengan baik. DAP digunakan untuk melihat konsep diri partisipan di awal dan di akhir penelitian dengan memperhatikan aspek-aspek dalam gambar yang berkaitan dengan konsep diri seperti ukuran gambar, gambar tangan, dan gambar kaki.

\section{HASIL DAN PEMBAHASAN}

Setelah menjalani lima sesi intervensi yang dijalankan pada partisipan H, F, R, G, dan B, ditemukan adanya perubahan konsep diri yang menjadi lebih baik pada kelima remaja di LPKA SLM. Hal ini ditunjukkan dengan munculnya pengenalan terhadap diri masing-masing partisipan, meningkatnya kepercayaan diri mereka, munculnya keinginan untuk berubah, dan munculnya insight mengenai solusi terhadap permasalahan mereka saat ini.

H menunjukkan ketertarikan saat berada di kelompok dengan merespon saat diberikan pertanyaan oleh peneliti. Sepanjang intervensi, H cukup inisiatif dalam menjawab dan serius dalam mengikuti intervensi. H cukup terbuka dengan partisipan lainnya dan mampu untuk mengungkapkan kondisinya. Namun, pada sesi ketiga $\mathrm{H}$ tidak dapat langsung mengungkapkan tujuannya secara spesifik, ia memiliki tujuan namun tidak dapat menjelaskan langkah-langkah yang akan dilakukan. Pada sesi keempat dan kelima, H mampu untuk mengungkapkan solusi yang telah ia pikirkan dengan baik. $\mathrm{H}$ mampu mengungkapkan solusi yang dapat dilakukan dan merupakan pengalamannya dari mengikuti kegiatan di LPKA SLM. H juga mampu menyadari hal-hal apa 
yang menjadi solusi bagi dirinya dapat membuat $\mathrm{H}$ menjadi lebih percaya diri untuk masuk ke dalam lingkungan sosial nantinya.

F menunjukkan ketertarikan saat berada di kelompok dengan merespon saat diberikan pertanyaan oleh peneliti. F terlihat kurang nyaman dan kurang percaya diri pada sesi pertama dan kedua, yang ditunjukkan dengan hanya tertawa dalam menanggapi pernyataan partisipan lain, tidak mengobrol dengan partisipan lain, kecuali dengan $\mathrm{R}$ yang merupakan teman satu perkaranya, suara yang kecil, dan sering menunduk ketika menjawab. Pada sesi ketiga, F mulai lebih berinteraksi dengan partisipan lain. F mampu untuk berbicara tanpa menunduk dengan terapis atau dengan partisipan lain. F masih kurang mampu menilai kondisinya saat ini, namun mulai mengungkapkan penyesalan atas perilakunya dan cita-citanya. Pada sesi kelima, F mampu memikirkan dan mengungkapkan perubahan-perubahan apa yang harus ia lakukan dan sadar bahwa hal-hal yang ia dapat dari kelompok mampu memperbaiki pandangannya terhadap diri sendiri.

$\mathrm{R}$ menunjukkan ketertarikan saat berada di kelompok dengan merespon saat diberikan pertanyaan oleh peneliti dengan inisiatif. $\mathrm{R}$ merupakan salah satu partisipan yang aktif didalam kelompok. $\mathrm{R}$ sangat sopan dan terbuka dengan partisipan lain, ia juga tidak malu untuk mengungkapkan apa yang ia pikirkan. Pada sesi keempat, $\mathrm{R}$ terlihat murung ketika membahas solusi yang harus dilakukan. $\mathrm{R}$ mampu menyadari hal-hal apa saja yang harus ia lakukan dan mengetahui pengaruhnya terhadap dirinya. Setelah sesi, R mengungkapkan bahwa ia cukup sedih ketika membahas hal-hal apa saja yang seharusnya ia lakukan karena ia merasa terlambat untuk menyadarinya. Pada sesi kelima, R lebih percaya diri untuk masuk ke masyarakat dan mengetahui apa saja yang harus ia lakukan nantinya.

G menunjukkan kurang ketertarikan saat berada di kelompok. G kurang inisiatif dalam menjawab dan terlihat kurang nyaman dengan partisipan lain. Pada sesi kedua, G juga kurang mampu untuk menjelaskan kejadian yang membuatnya merasa baik dan masih kurang dalam pengenalan diri. $G$ mulai menjawab pertanyan dengan serius pada sesi keempat. $G$ mengetahui hal-hal apa yang harus ia lakukan untuk mengatasi masalahnya. $G$ diakhir sesi juga telah dapat menyebutkan keinginan yang ingin dicapainya dalam hidup.

B menunjukkan kurang ketertarikan dan kurang nyaman di dalam kelompok. B diawal pertemuan juga belum mengenal partisipan lain dan memiliki kasus yang berbeda dengan partisipan lainnya. B kurang inisiatif dan cenderung menjawab dengan seadanya saja. Pada sesi ketiga, B menunjukkan sikap yang pesimistis dalam menjawab miracle question. Pada sesi keempat dan kelima, solusi yang diberikan oleh B cenderung ke arah pendekatan agama dan menyadari bahwa hal tersebut dapat merubah diri dan pandangan orang lain terhadapnya.

Hasil pre-test dan post-test dari tes DAP juga menunjukkan adanya perubahan. Pada pre-test seluruh peserta menggambar orang pada tes DAP dengan ukuran yang cenderung kecil, letak yang berada di kiri, tidak menggambar tangan, dan bagian kaki yang terpotong atau tidak digambar. Kemudian, pada hasil post-test terdapat perubahan dan hal-hal yang berubah pada gambar yang dibuat oleh peserta termasuk letak gambar lebih ke arah tengah kertas, ukuran gambar yang lebih besar, proposi leher yang lebih baik, bentuk tangan tergambar terbuka disamping tubuh, dan adanya gambar kaki. Ukuran gambar yang lebih besar menunjukkan tumbuhnya rasa percaya diri pada partisipan. Leher menunjukkan adanya kontrol antara pikiran dan perilaku. Bentuk tangan dan kaki menunjukkan adanya perasaan berdaya pada partisipan. Seluruh hal ini mengindikasikan adanya konsep diri yang lebih baik pada masing-masing partisipan. 


\section{KESIMPULAN DAN SARAN}

Berdasarkan hasil yang didapatkan, maka dapat disimpulkan bahwa solution-focused brief therapy dengan pendekatan kelompok cukup efektif untuk memperbaiki konsep diri pada remaja di LPKA SLM. Konsep diri yang semakin baik dapat dilihat dari hasil tes grafis Draw a Person (DAP) dan observasi yang dilakukan selama sesi intervensi berlangsung. Perubahan dalam tes DAP yang terjadi dapat dilihat dari perubahan gambar orang yang dibuat oleh para peserta berdasarkan letak, bentuk, arah, dan coretan garis yang dilakukan oleh para peserta. Perubahan tersebut mengindikasikan adanya konsep diri yang lebih baik, perasaan berdaya, dan lebih percaya diri.

Saran untuk penelitian selanjutnya disarankan untuk menggunakan ruangan yang bebas dari gangguan. Hal ini dibutuhkan agar seluruh partisipan dapat fokus menjalani setiap proses terapi dan tidak terganggu oleh hal-hal yang tidak diinginkan. Kedua, penelitian selanjutnya disarankan untuk melakukan proses bina rapport yang lebih mendalam agar seluruh partisipan di dalam kelompok dapat lebih mengenal dan akrab satu sama lain. Terakhir, penelitian selanjutnya disarankan untuk menggunakan alat ukur terkait dengan konsep diri. Hal ini ditujukkan agar dalam penelitian selanjutnya, hasil dari intervensi dapat diukur secara kuantitatif.

\section{Ucapan Terima Kasih}

Peneliti berterima kasih kepada kelima partisipan dan pihak dari LPKA SLM yang terlibat dan bekerja sama dengan peneliti selama proses penelitian yang dilakukan. Selain itu, peneliti juga berterima kasih kepada berbagai pihak yang telah membantu dalam penelitian ini.

\section{REFERENSI}

Biggs, H. C., \& Flett, R. A. (2005). Rehabilitation professionals and solution-focused brief therapy. Proceeding of the Inaugural Australian Counseling and Supervision Conference (pp. 12-18). Queensland University of Technology, Australia.

Brabender, V. M., Smolar, A. I., \& Fallon, A. E. (2004). Essentials of group therapy. Hoboken, NJ: John Wiley \& Sons.

Calhoun, J.F \& Acocella, J. R. (1990). Psychology of adjustment and human relationships. New York, NY: McGraw-Hill.

Cattell, R. B. (1949). Culture fair intelligence test, scale 1. Champaign, IL: Institute of Personality and Ability Testing.

Kim, J. S. (2008). Examining the effectiveness of solution-focused brief therapy: A metaanalysis. Research on Social Work Practice, 18(2), 107-116.

Machover, K. (1949). Personality projection in the drawing of the human figure: A method of pesonality investigation. Springfield, Il: Charles C. Thomas.

Omotunde, E. E., Akporobaroh, O. W., \& Odunayo, A. J. (2017). Effect of Solution Focused Brief Therapy on Adolescents' Self Concept among Secondary School Students in IkpobaOkha Local Government Area in Edo State. American Journal of Educational Research, 5(11), 1162-1166.

Papalia D.E., Olds, S.W, \& Feldman, R.D. (2009). Human development. New York, NY: McGraw-Hill.

Roeden, J. M., Maaskant, M. A., \& Curfs, L. M. G. (2014). Processes and effects of SolutionFocused Brief Therapy in people with intellectual disabilities: a controlled study. Journal of Intellectual Disability Research, 58(4), 307-320.

Santrock, J. W. (2012). Lifespan developmental psychology. New York, NY: McGraw-Hill.

Schoot, R.V., \& Wong, T. M. (2012). Do delinquent young adults have a high or a low level of self-concept?. Self and Identity, 11(2), 148-169. 